\title{
Porous Silicon Structural Evolution from In-Situ Luminescence and Raman Measurements
}

D. R. Tallant, M. J. Kelly, T. R. Guilinger and R. L. Simpson Sandia National Laboratories, P.O. Box 5800, Albuquerque, NM 87185-1411

$$
\begin{aligned}
& \text { EONF-960401--24 }
\end{aligned}
$$

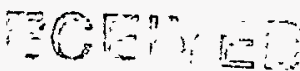

$$
\begin{aligned}
& \text { 3.9.9 } 12 \mathrm{~km}
\end{aligned}
$$

\section{ABSTRACT}

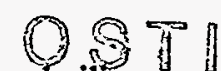

We performed in-situ photoluminescence and Raman measurements on an anodized silicon surface in the HF/ethanol solution used for anodization. The porous silicon thereby produced, while resident in $\mathrm{HF} /$ ethanol, does not immediately exhibit intense photoluminescence. Intense photoluminescence develops spontaneously in HF/ethanol after 18-24 hours or with replacement of the HF/ethanol with water. These results support a quantum confinement mechanism in which exciton migration to traps and nonradiative recombination dominates the de-excitation pathways until silicon nanocrystallites are physically separated and energetically decoupled by hydrofluoric acid etching or surface oxidation. The porous silicon surface, as produced by anodization, shows large differences in photoluminescence intensity and peak wavelength over millimeter distances. Parallel Raman measurements implcate nanometer-size silicon particles in the photoluminescence mechanism.

\section{INTRODUCTION}

Photoluminescence (PL) from porous silicon has been extensively studied, but its mechanism is the subject of continued controversy. Various workers have proposed that porous silicon PL originates in the quantum size effect of nanocrystalline silicon domains [1- 5], hydrogenated silicon structures [6] and siloxene species [7]. Generally, porous silicon PL is measured on samples that have been anodized and then dried in air. However, removal from the anodization solution and subsequent drying with concomitant air exposure is a form of post-anodization treatment that can have strong effects on the PL. We have separated the effects of anodization and post-anodization treatment by in-situ monitoring of porous silicon PL (and, in a parallel experiment, Raman scatter) during and after anodization with the porous silicon still resident in the anodization solution.

\section{EXPERIMENT}

Silicon wafers $(10-\mathrm{cm}$ diameter, $<100>$ p-type, $0.5-1.0 \mathrm{ohm}-\mathrm{cm})$ were anodized in a $15-\mathrm{cm}$ square Teflon cell with a 7.5-cm diameter sapphire window for optical access. The cell has a platinum mesh cathode mounted immediately behind the sapphire window. A horizontal strip was cut from the platinum cathode to provide optical access to the silicon wafer behind it. We anodized each silicon wafer for 13 minutes at $30 \mathrm{~mA} / \mathrm{cm}^{2}$ in 1.25:1 HF(49\%):ethanol solution with the room darkened. Films resulting from these anodization conditions are typically $20 \mu \mathrm{m}$ thick and $80 \%$ porous. PL and Raman spectra were obtained using a $0.6-\mathrm{m}$ spectrograph and liquid-nitrogen-cooled charge-coupled detector. This spectrograph was operated at $1 \mathrm{~nm}$ resolution for PL measurements and $5 \mathrm{~cm}^{-1}$ resolution for Raman measurements. An argon ion laser, whose beam was focused to an approximately $2 \mathrm{~mm}$ by $0.1 \mathrm{~mm}$ rectangle, was used to excite both PL and Raman scatter. PL was excited with $0.5 \mathrm{~mW}$ of the $458 \mathrm{~nm}$ line resulting in a relatively low irradiance of $250 \mathrm{~mW} / \mathrm{cm}^{2}$ at the silicon surface in order to minimize photochemical reactions. To obtain good-quality Raman spectra, it was necessary to irradiate at a higher intensity $\left(5 \mathrm{~W} / \mathrm{cm}^{2}\right)$, using $10 \mathrm{~mW}$ of the $514 \mathrm{~nm}$ line. We suppressed laser scatter using a long-pass filter to measure PL and a notch filter for Raman spectra. PL spectra have been corrected for

\section{MASTEh}




\section{DISCLAIMER}

This report was prepared as an account of work sponsored by an agency of the United States Government. Neither the United States Government nor any agency thereof, nor any of their employees, make any warranty, express or implied, or assumes any legal liability or responsibility for the accuracy, completeness, or usefulness of any information, apparatus, product, or process disclosed, or represents that its use would not infringe privately owned rights. Reference herein to any specific commercial product, process, or service by trade name, trademark, manufacturer, or otherwise does not necessarily constitute or imply its endorsement, recommendation, or favoring by the United States Government or any agency thereof. The views and opinions of authors expressed herein do not necessarily state or reflect those of the United States Government or any agency thereof. 


\section{DISCLAMMER}

Portions of this document may be illegible in electronic image products. Images are produced from the best available original document. 
instrument response. The background due to PL has been fitted and removed from the Raman spectra.

\section{RESULTS}

\section{Photoluminescence (PL)}

In these experiments PL was monitored during and after anodization with the anodized wafer still immersed in the (HF/ethanol) anodization solution. Near the end of the experiment, the anodization solution was replaced with water. In one experiment, PL from the anodized wafer was monitored, at intervals, for 24 hours after anodization while residing in the anodization solution. In another experiment the anodization solution was replaced with water about an hour after anodization, and, after PL measurements, the silicon wafer was again immersed in the anodization solution. As will be subsequently discussed, irradiation during anodization with even the low levels of excitation used to excite PL affected the formation of thick porous silicon layers. Consequently, we monitored areas irradiated during anodization and areas not irradiated during anodization.

In the first (24-hour duration) experiment, one area was irradiated (and PL measured) intermittently during anodization with $250 \mathrm{~mW} / \mathrm{cm}^{2}$ of $458 \mathrm{~nm}$ laser light. The surface of the silicon was irradiated for a total of three minutes during the 13-minute anodization. Figure 1 shows PL from this area of the silicon surface prior to, during and immediately after anodization. Prior to anodization the PL peaks in the blue $(<500 \mathrm{~nm})$ and is extremely low in intensity, at the level of Raman scatter from the anodization solution (Raman bands due to $\mathrm{O}-\mathrm{H}$ and $\mathrm{C}-\mathrm{H}$ vibrations are labeled in the figure). During and after the anodization the PL peak shifts to the green, and its intensity increases by several times. After anodization the PL intensity is still relatively low, about 30 times less than what is normally measured for porous silicon after longterm air exposure. The PL at this location then decreased in intensity for measurements up to 200 minutes. When next measured, after 1100 minutes in the anodization solution, the PL was several times more intense, with a further increase in intensity and red-shift after 1400 minutes (Figure 2). At 1440 minutes, after replacement of the HF/ethanol anodization solution with water, the PL (Figure 2) showed a large increase in intensity and further red shift.

We also monitored the PL at two areas one millimeter on either side of the area irradiated and monitored during anodization. These areas received no illumination during anodization. Immediately after anodization (time $=13$ minutes), the intensity of the PL from these areas was unchanged from pre-anodization levels. At 1100 minutes after anodization these areas, like the area irradiated during anodization, showed similar, spontaneous increases in PL intensity, and at 1300 minutes these areas emitted more intensely than the area irradiated during anodization. Integrated PL intensities for the three areas are plotted versus residence time in the anodization solution in Figure 3. Both sets of areas, the one irradiated and those not irradiated during anodization, exhibited a four-to-five times increase in their integrated PL intensity on subsequent exposure to water (not shown in Figure 3). The final PL intensities (in water) are similar to those obtained from wafers anodized using similar conditions but dried in air.

Porous silicon PL was also measured in-situ before, during and after anodization in an experiment of shorter duration, which was designed to focus on the effects of exposure to water and re-exposure to the HF/ethanol anodization solution. In this experiment one area on the surface of the silicon wafer was irradiated (and PL monitored) continuously during the 13-minute anodization with $250 \mathrm{~mW} / \mathrm{cm}^{2}$ of $458 \mathrm{~nm}$ laser light. PL spectra from this area and two separate areas one millimeter on either side of it were obtained intermittently until 55 minutes after 
initiation of anodization. Then the anodization solution was replaced with water. At 85 minutes the water was drained and the cell refilled with HF/ethanol solution.

Integrated PL intensities for the three areas are plotted versus time after initiation of anodization in Figure 4. As with the experiment of 24-hour duration, anodization by itself did not result in intense PL. During and after anodization there was no increase in PL intensity at any of the three areas, but, after 50 minutes, the area irradiated during anodization and one of the areas not so irradiated show a two to three times increase in PL intensity. A 40-100 fold increase in PL intensity occurred at all three areas after exposure to water at 55 minutes into the experiment. Subsequent re-exposure to HF/ethanol reduces the PL intensity at all three areas by an order of magnitude. Note that, except for the measurement during water exposure, the PL intensity versus time from the area irradiated during anodization forms a slowly rising curve. The effects of water exposure appear to be largely reversed by re-exposure to HF/ethanol. Unlike the 24-hour experiment, the PL from the two areas not irradiated during anodization is different not only from that of the area irradiated during anodization but also from each other, both in intensity (Figure 4) and wavelength (higher intensity peak at $645 \mathrm{~nm}$, lower intensity peak at $685 \mathrm{~nm}$ )

\section{$\underline{\text { Raman Spectra }}$}

In an experiment executed similarly to the short-duration experiment in which PL measurements were made, we obtained in-situ Raman spectra of the anodized silicon surface. A small rectangle was illuminated with $250 \mathrm{~mW} / \mathrm{cm}^{2}$ of $458 \mathrm{~nm}$ laser light continuously during the 13-minute anodization. Subsequent to the anodization, areas of the same size were illuminated with $5 \mathrm{~W} / \mathrm{cm}^{2}$ of $514 \mathrm{~nm}$ laser light for 60 -second intervals, during which Raman spectra were obtained both in the area irradiated during anodization and in areas not so irradiated. Raman spectra of areas not irradiated during anodization showed a broadening and shifting of the fundamental silicon Raman band (Figure 5) to lower frequency, suggesting the formation of nanocrystalline silicon phases with dimensions in the 5-10 nm range [8]. Similar broadening and down-shifting of the silicon Raman band in porous silicon have been previously observed $[9,10]$. After exposure to water (and also with re-exposure to $\mathrm{HF} /$ ethanol) the Raman spectra have a dominant band coincident with that of the pre-anodization silicon but with a distinct shoulder extending to $480 \mathrm{~cm}^{-1}$. Similar silicon Raman band shapes have been obtained for largely crystalline polysilicon films with nanometer-size faults or dislocations [11] and for crystalline silicon inclusions with nanoscale surface layers in a silicon dioxide matrix [12]. The Raman spectrum of the area irradiated during anodization showed no significant changes in the silicon Raman band from the pre-anodization spectrum, but this does not preclude the existence of nanocrystalline silicon as a coating too thin for detection by Raman spectroscopy (tens of nanometers or less).

\section{CONCLUSIONS}

An unexpected result of this work is the lack of intense PL from the anodized silicon surface in HF/ethanol immediately after anodization. The Raman spectra indicate that nanocrystalline silicon is being formed on the wafer surface during anodization, at least in areas not intentionally irradiated during anodization. According to the quantum confinement theory, these nanocrystallites should be capable of emitting intense PL in the visible wavelength region. Since intense PL occurs only after extensive residence in the anodization solution, chemical etching by $\mathrm{HF}$ is what we believe causes the silicon nanocrystals formed during anodization to eventually emit visible light. However, if the etching were merely reducing the size of all the nanocrystals, we would expect a blue shift in wavelength as the intense PL develops, not the observed red shift (Figure 2). During extended residence in the anodization solution, HF etching changes the overall 
size distribution of silicon nanocrystals and physically separates them by dissolving surfaces in contact. Silicon nanocrystals capable of emitting visible PL may be produced by the anodization, but their emission is quenched by migration of excitons to traps. As produced, the silicon nanocrystals are in close contact and energetically coupled to adjacent nanocrystals, allowing fast migration of excitons generated by incident light photons through the silicon matrix to trapping sites, where they nonradiatively combine. Etching by hydrofluoric acid dissolves some nanocrystals and also separates nanocrystals by attacking cracked or stressed regions, reducing the coupling between nanocrystals and lowering the rate of exciton migration. As nanocrystals are isolated from the silicon matrix, there will be a higher probability of radiative recombination of excitons, as was observed by Teschke et al.[13].

Reaction of the porous silicon surface with oxygen in water (without HF present) or air will result in surface oxidation and should yield a similar isolation of the nanocrystallites. PL from isolated silicon nanocrystals in oxide matrices has been reported $[14,15]$. Thus, air drying, as usually occurs prior to porous silicon PL measurements and water exposure, as described in this manuscript, should, as observed, enhance the intensity of PL emitted from porous silicon. Subsequent re-exposure to HF/ethanol removes the oxide from the surface of the porous silicon, returning it to a state like that prior to water exposure in which nonradiative recombination of excitons is favored. As Figure 4 shows, this results in a drop in PL intensity.

Illumination during anodization suppresses the formation of thick layers of nanocrystalline silicon (photo-etching is suspected); but even those areas intentionally irradiated during anodization must have a thin layer of porous silicon, since they also emit PL. In fact, at short residence times in $\mathrm{HF} / \mathrm{ethanol}$, the most intense emission comes from areas irradiated during anodization, probably because those nanocrystallites present after anodization are relatively isolated.

Finally, researchers should note the differences in emission from the two apparently identically treated areas two millimeters apart on the wafer that resided in the anodization solution less than two hours (Figure 4). A single point measurement from a porous silicon surface is not necessarily representative of the sample as a whole. However, the etching accompanying extended residence in HF/ethanol may homogenize the porous silicon surface (Figure 3).

\section{ACKNOWLEDGMENTS}

This work was performed at Sandia National Laboratories, which is operated for the U. S. DOE under contract \# DE-AC04-94AL85000.

\section{FIGURE CAPTIONS}

1. PL spectra from the silicon surface in HF/ethanol before, during and immediately after anodization. Raman bands from the HF/ethanol solution are marked "C-H" and "O-H".

2. PL spectra of the same area whose spectra are shown in Figure 1, obtained immediately after anodization and at 1100 and 1400 minutes in $\mathrm{HF} / \mathrm{ethanol}$ and at 1440 minutes in water. The intensity scale is the same as Figure 1.

3. Integrated PL intensities (arbitrary units) versus time for areas irradiated ( $\square$ ) and not irradiated $(+, x)$ during anodization, with the silicon surface continuously immersed in HF/ethanol.

4. Integrated PL intensities (same scale as Figure 3) versus time for areas irradiated (solid) and not irradiated (dashed) during anodization. The silicon surface was continuously immersed in HF/ethanol for 55 minutes, then exposed to water and finally re-immersed in HF/ethanol at 85 minutes. 
5. Raman band (Si fundamental) of an area not illuminated during anodization; in HF ethanol before anodization (solid), in HF/ethanol after 61 minutes $(+)$ and in water after 108 minutes (dashed).

\section{REFERENCES}

1. L.T. Canham, Appl. Phys. Lett. 57, 1046 (1990).

2. A. G. Cullis and L. T. Canham, Nature 353, 335 (1991).

3. S. Gardelis, J. S. Rimmer, P. Dawson, B. Hamilton, B. R. Kubiak, T. E. Whall and E. H. C. Parker, Appl. Phys. Lett. 59, 2118 (1991).

4. T. Van Buren, Y. Gao, T.Tiedje, J. R. Dahn and B. M. Way, Appl. Phys. Lett. 60, 3013 (1992).

5. S. V. Bhat, K. Jayaram, D. V. S. Muthu and A. K. Sood, Appl. Phys. Lett. 60, 2116 (1992).

6. C. Tsai, K.-H. Li, D. S. Kinosky, R.-Z. Qian,T.-C. Hsu, J. T. Irby, S. K. Banerjee, A. F. Tasch, J. C. Campbell, B. K. Hance and J. M. White, Appl. Phys. Lett. 60, 1700 (1992).

7. M. S. Brandt, H. D. Fuchs, M. Stutzmann, J. Weber and M. Cardona, Solid State Commun. 81,307 (1992).

8. F. H. Pollak, Test and Measurement World, May, 1985, pp. 2-10.

9. Z. Sui, P. P. Leong, I. P. Herman, G. S. Higashi and H. Temkin, Appl. Phys. Lett. 60(17) 2086-8 (1992).

10. R. Tsu, H. Shen and M. Dutta, Appl. Phys. Lett. 60(1), 112-4 (1992).

11. D. R. Tallant, T. J. Headley, J. W. Medernach and F. Geyling, Mat. Res. Soc. Symp. Proc., Vol. 324, 255 (1994).

12. D. J. Olego and H. Baumgart, J. Appl. Phys. 63(8), 2669 (1988).

13. O. Teschke, F. Alvarez, L. Tessler and M. V. Kleinke, Appl. Phys. Lett. 63(14), 1927 (1993).

14. W. Cao and A. J. Hunt, Appl. Phys. Lett. 64(18), 2377-9, (1994).

15. Q. Zhang, S. C. Bayliss and D. A. Hutt, Appl. Phys. Lett. 66(15), 1977-9 (1995).

\section{DISCLAIMER}

This report was prepared as an account of work sponsored by an agency of the United States Government. Neither the United States Government nor any agency thereof, nor any of their employees, makes any warranty, express or implied, or assumes any legal liability or responsibility for the accuracy, completeness, or usefulness of any information, apparatus, product, or process disclosed, or represents that its use would not infringe privately owned rights. Reference herein to any specific commercial product, process, or service by trade name, trademark, manufacturer, or otherwise does not necessarily constitute or imply its endorsement, recommendation, or favoring by the United States Government or any agency thereof. The views and opinions of authors expressed herein do not necessarily state or reflect those of the United States Government or any agency thereof. 

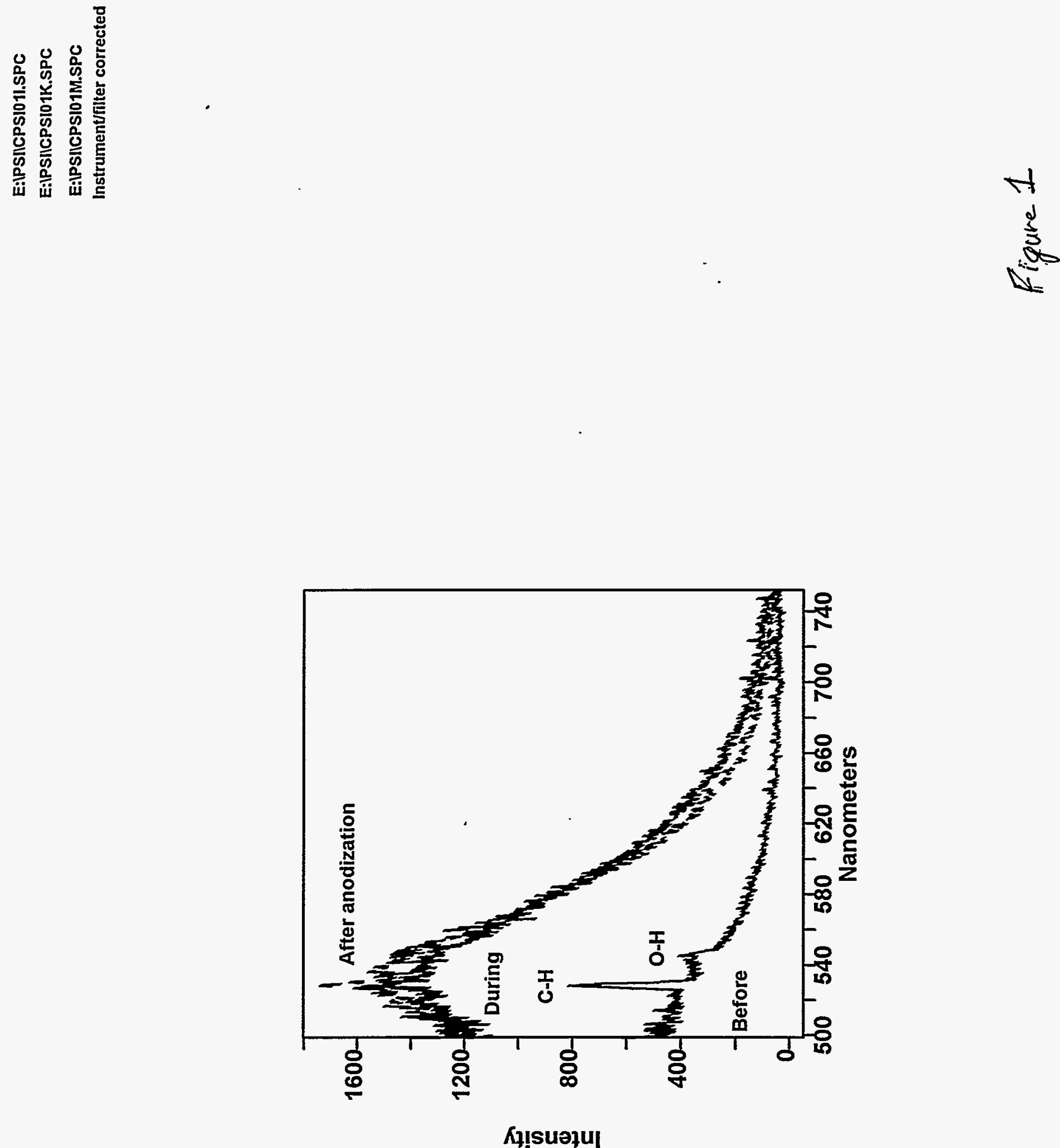
E:IPSICPSI02S.SPC

E:IPSIICPSIO2K.SPC

E:IPSICPSI02E.SPC

E:IPSIICPSI01M.SPC

Irradiated during anodization

Water refill at 1420 minutes

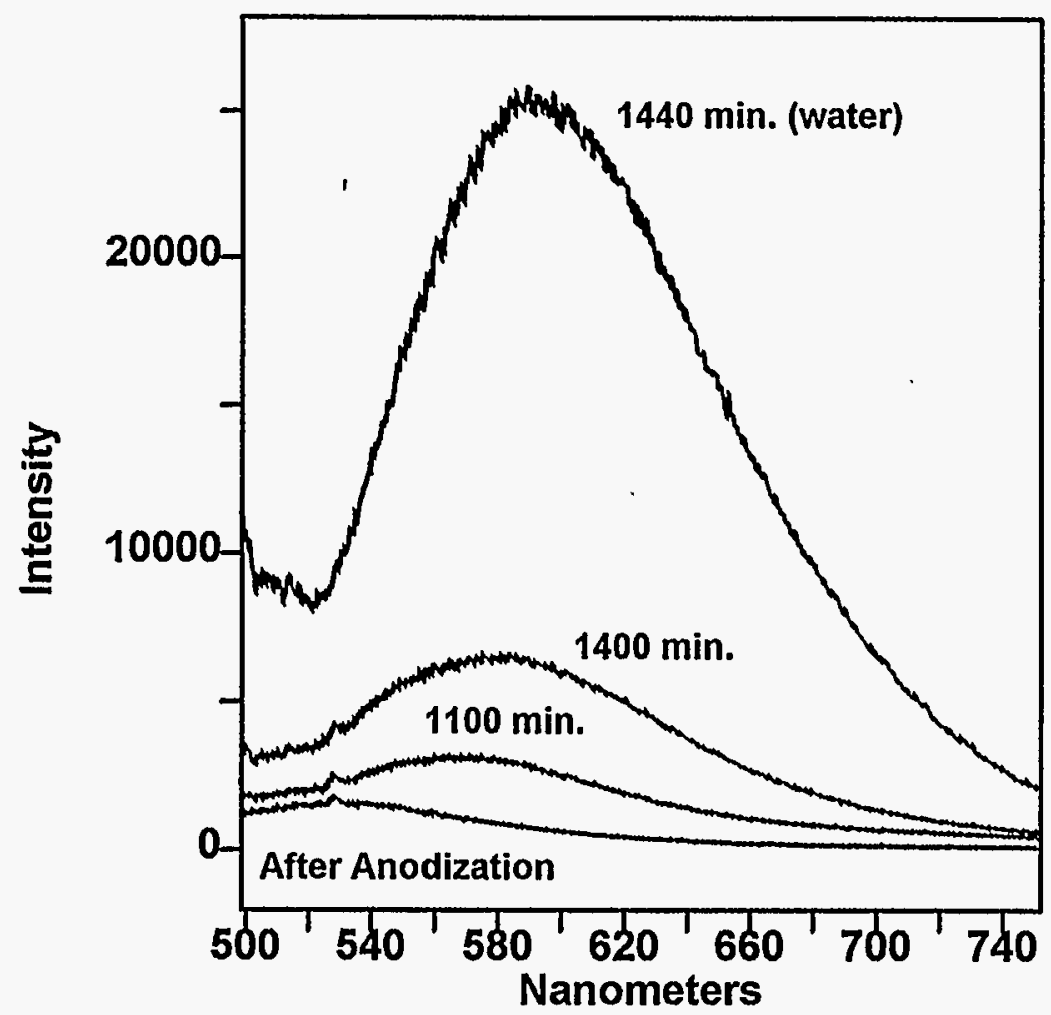

Figure 2 

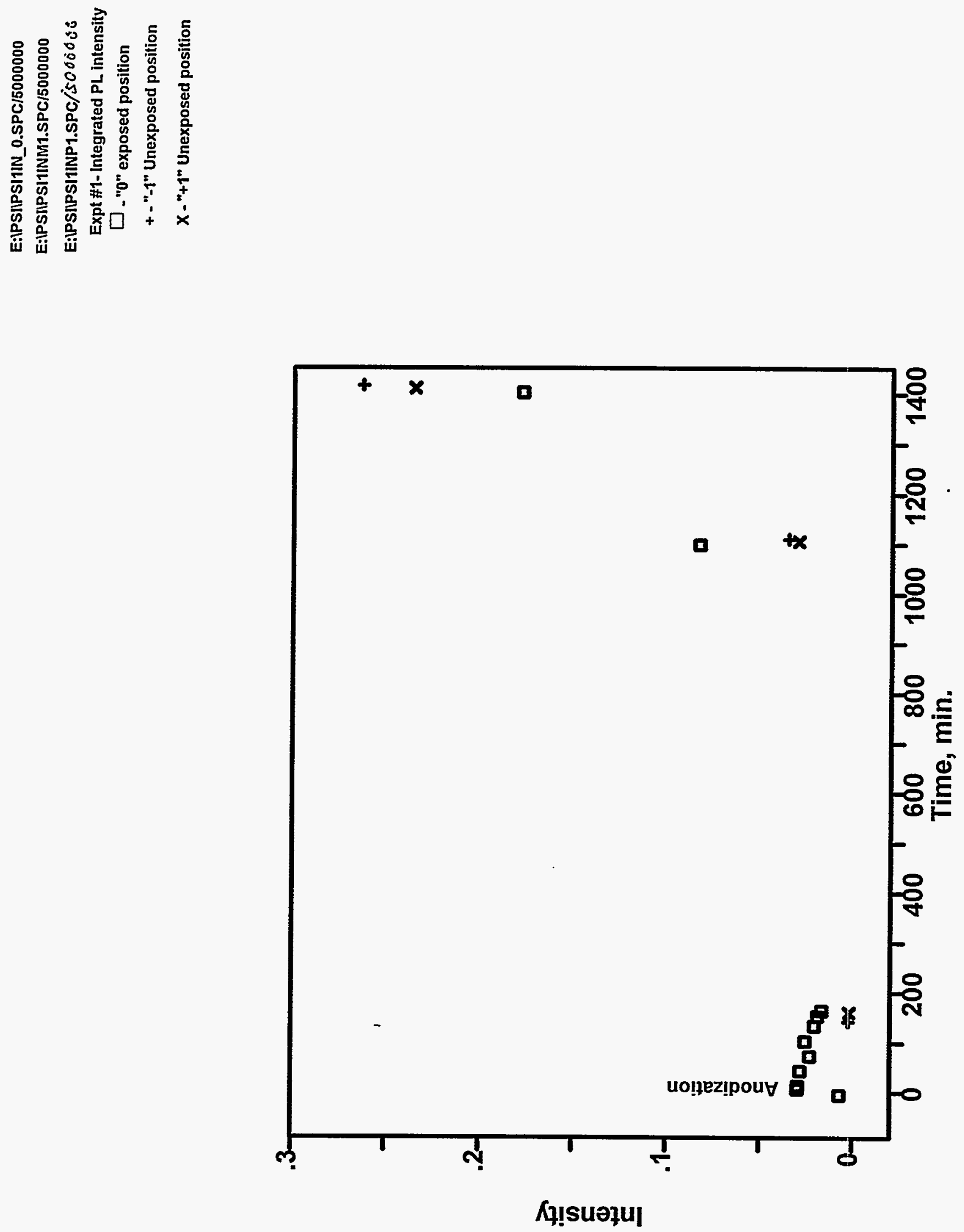
Solid - "0" exposed area

dashed $\left\{\sum^{n+1 " \text { Unexposed area }}\right.$

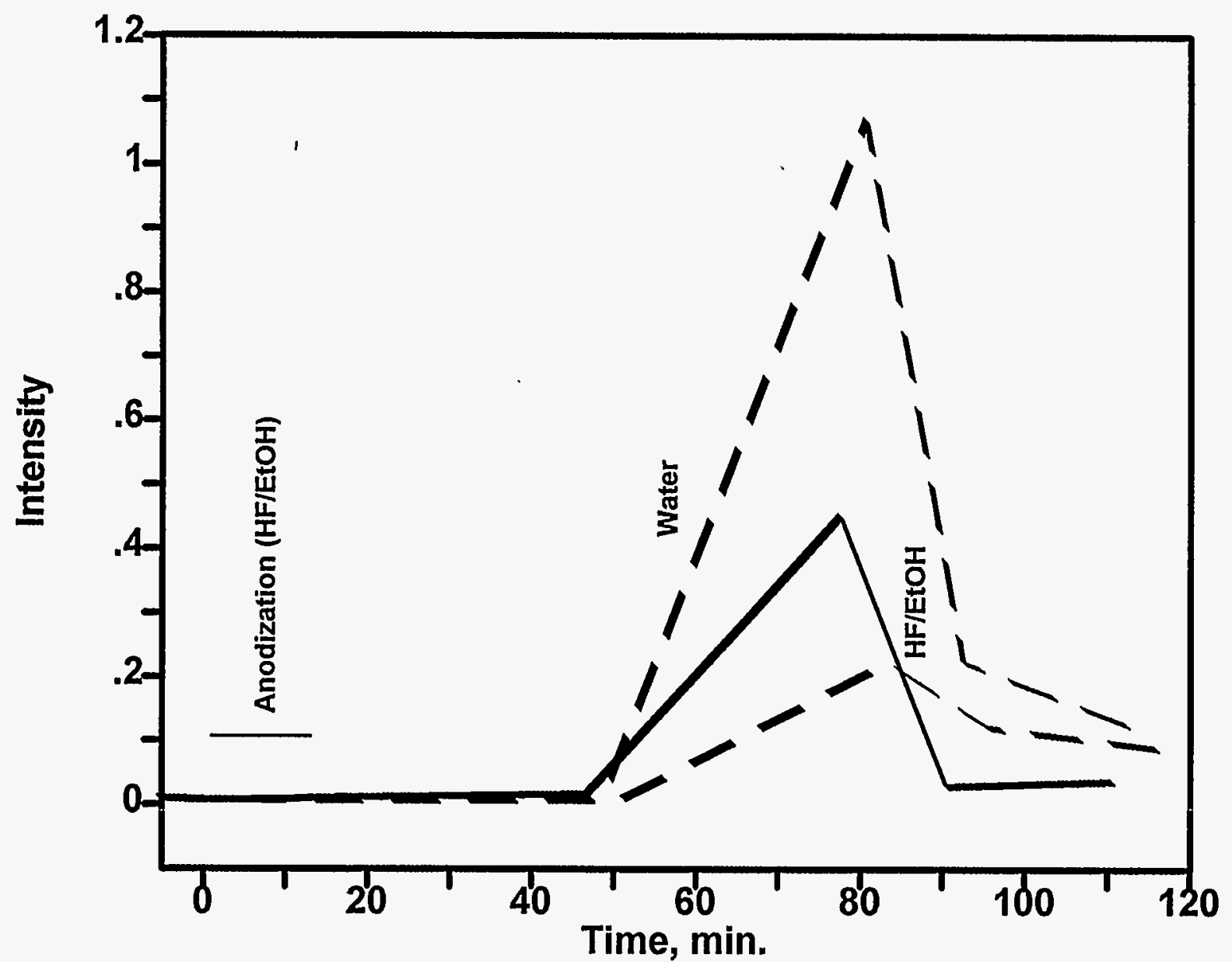

Figure 4 
E:IPSIIBPSI04D.SPC $\times 0.330$

E:IPSIIBPSI04L.SPC

E:IPSIIBPSI04VX.SPC $\times 0.97$

Similar to Exp't \#2

"-1" unexposed

Pre-anodization

+++ HFlethanol, $61 \mathrm{~min}$.

- - Water, $108 \mathrm{~min}$.

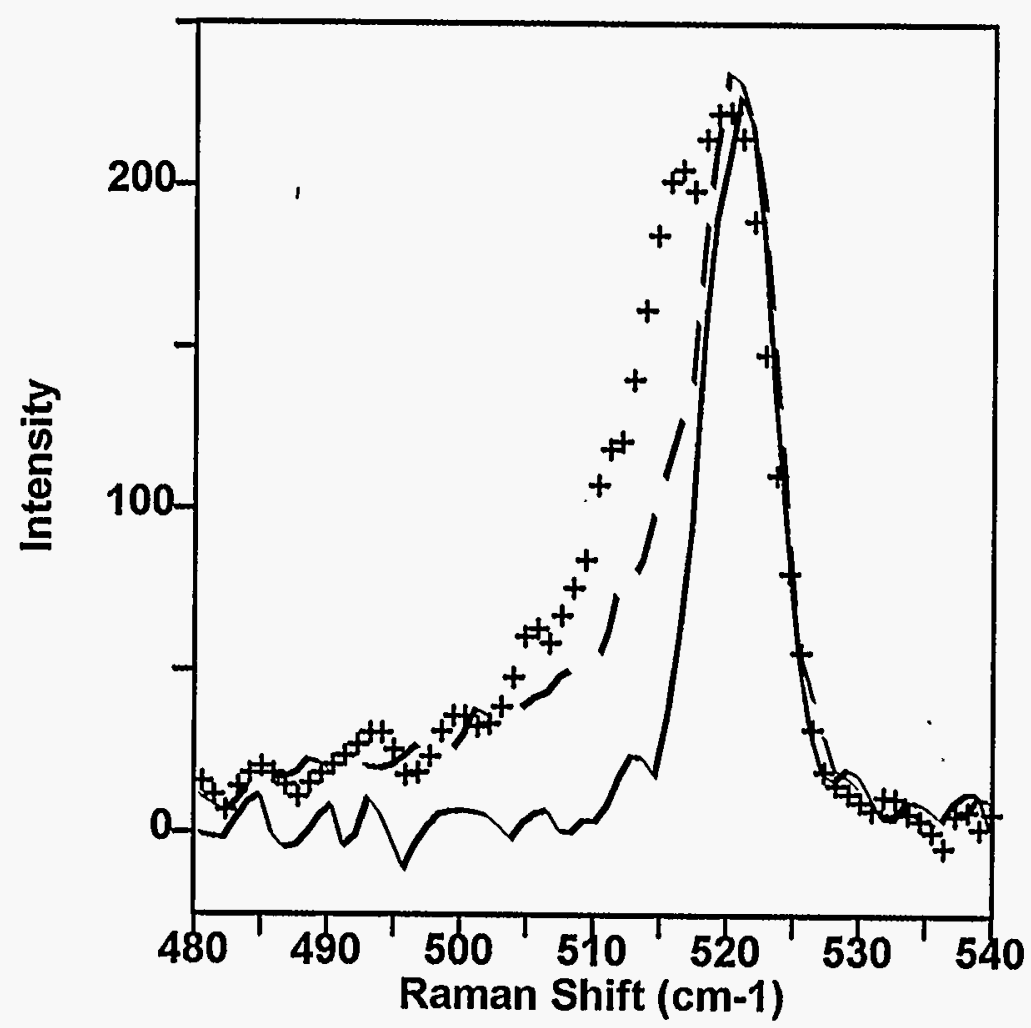

Figure 5 